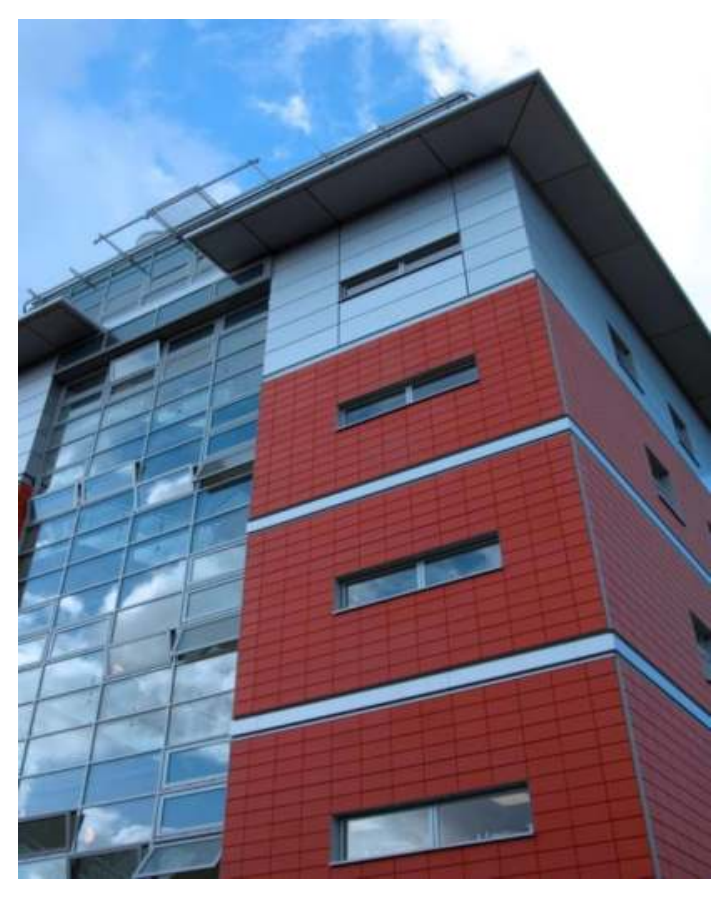

\title{
De Novo, Non-Donor Specific HLA Antibodies are Associated with Inferior Allograft Outcomes after Kidney and Simultaneous Kidney-Pancreas Transplantation
}

\author{
Sevda Hassan ${ }^{1}$, Gaetano Lucisano ${ }^{1}$, Eva Santos 2 , Nicola Firmin², Denise Mckeown ${ }^{3}$, Dawn \\ Goodall, Alexander Gueret-Wardle ${ }^{1}$, Adam McLean ${ }^{1}$, Paul Brookes ${ }^{2}$, Michelle Willicombe ${ }^{1}$, \\ David Taube ${ }^{1}$
}

${ }^{1}$ Renal and Transplant Centre, Imperial College Healthcare NHS Trust, London, UK

${ }^{2}$ Histocompatibility and Immunogenetics, Imperial College Healthcare NHS Trust, London, UK

${ }^{3}$ Blood Transfusion, Imperial College Healthcare NHS Trust, London, UK

Introduction: Donor specific antibodies [DSAs] occurring after transplantation are associated with poorer outcomes. However the significance of non-donor directed HLA antibodies [ndHLAs] after transplantation in unsensitised patients is less well understood. In this study, we establish the significance of ndHLAs in a large unsensitised cohort of transplant patients.

Methods: We retrospectively analysed 752 non-sensitised patients who underwent a kidney or SPK transplant from November 2005 to December 2015. All patients received monoclonal antibody induction, followed by tacrolimus monotherapy. Patients were screened for HLA and DSA at 3, 6, 12 months and yearly thereafter by Luminex technology. Positivity was defined as the presence of the antigen in at least 2 samples.

Results: The demographics of this unsensitised cohort can be seen in Table 1. 91/752 [12\%] developed ndHLAs; [Class I: 73\%, Class II: $24 \%$, Class I+II: $3 \%$ ]. Patients with ndHLAs were more likely to have rejection $[\mathrm{p}=0.004]$ and graft loss $[\mathrm{p}=0.005]$ (Fig1). This risk remained following correction for total mismatch, graft number and DGF [HR 1.85(1.20-2.86), $\mathrm{p}=0.005]$. Patient loss was not significant $[\mathrm{p}=0.072]$.

Mean tacrolimus levels post-transplant at six months and then annually were the same in both groups. In a subgroup of patients followed up to 48 months post transplant [ $n=432$ ] we observed significantly higher creatinine values at all time points $(6,12,24,36$ and 48 month) in the HLA positive group [p=0.011, ANOVA for repeated measures]. The presence of ndHLA was also significantly associated with $>50 \%$ C $4 \mathrm{~d}$ positivity $[\mathrm{p}=0.004]$ in transplant biopsies.

Multivariate analysis showed that previous pregnancies [OR 2.21(1.25-3.91), ), $\mathrm{p}=0.006]$ and transfusions within the first year of transplantation [OR 1.72(1.03-2.86), $\mathrm{p}=0.039$ ] were associated with Table 1. Demographics of the 752 non-sensitised transplant recipients

\begin{tabular}{|c|c|c|c|}
\hline & $\begin{array}{l}\text { HLA - DSA - } \\
{[\mathrm{n}=661]}\end{array}$ & $\begin{array}{l}\text { HLA+ DSA- } \\
{[\mathrm{n}=91]}\end{array}$ & p \\
\hline $\begin{array}{l}\text { Kidney } \\
\text { SPK }\end{array}$ & $\begin{array}{c}628 \\
33\end{array}$ & $\begin{array}{l}76 \\
15\end{array}$ & $<0.001$ \\
\hline $\begin{array}{c}\text { DBD } \\
\text { DCD } \\
\text { Live Transplant }\end{array}$ & $\begin{array}{c}305 \\
93 \\
163\end{array}$ & $\begin{array}{c}55 \\
6 \\
30\end{array}$ & 0.046 \\
\hline $\begin{array}{l}1^{\text {st }} \text { Transplant } \\
2^{\text {nd }} \text { Transplant }\end{array}$ & $\begin{array}{c}638 \\
23\end{array}$ & $\begin{array}{c}86 \\
5\end{array}$ & 0.369 \\
\hline $\begin{array}{c}\text { F, No prior } \\
\text { pregnancies } \\
\text { F, Previous } \\
\text { pregnancies } \\
\quad \text { Male }\end{array}$ & $\begin{array}{c}93 \\
70 \\
498\end{array}$ & $\begin{array}{l}11 \\
20 \\
60\end{array}$ & 0.007 \\
\hline $\begin{array}{c}\text { Age at } \\
\text { transplant }\end{array}$ & $50 \pm 13$ & $50 \pm 14$ & 0.473 \\
\hline DGF & 127 & 16 & 0.777 \\
\hline $\begin{array}{l}\text { Total mismatch, } \\
\text { median }\end{array}$ & $3(2-4)$ & $4(2-4)$ & 0.581 \\
\hline
\end{tabular}
ndHLA development. The median time to developing ndHLA from transplantation was 849 days [97-1882]; this was quicker in patients with previous pregnancies $[\mathrm{p}=0.018]$ (Fig2).

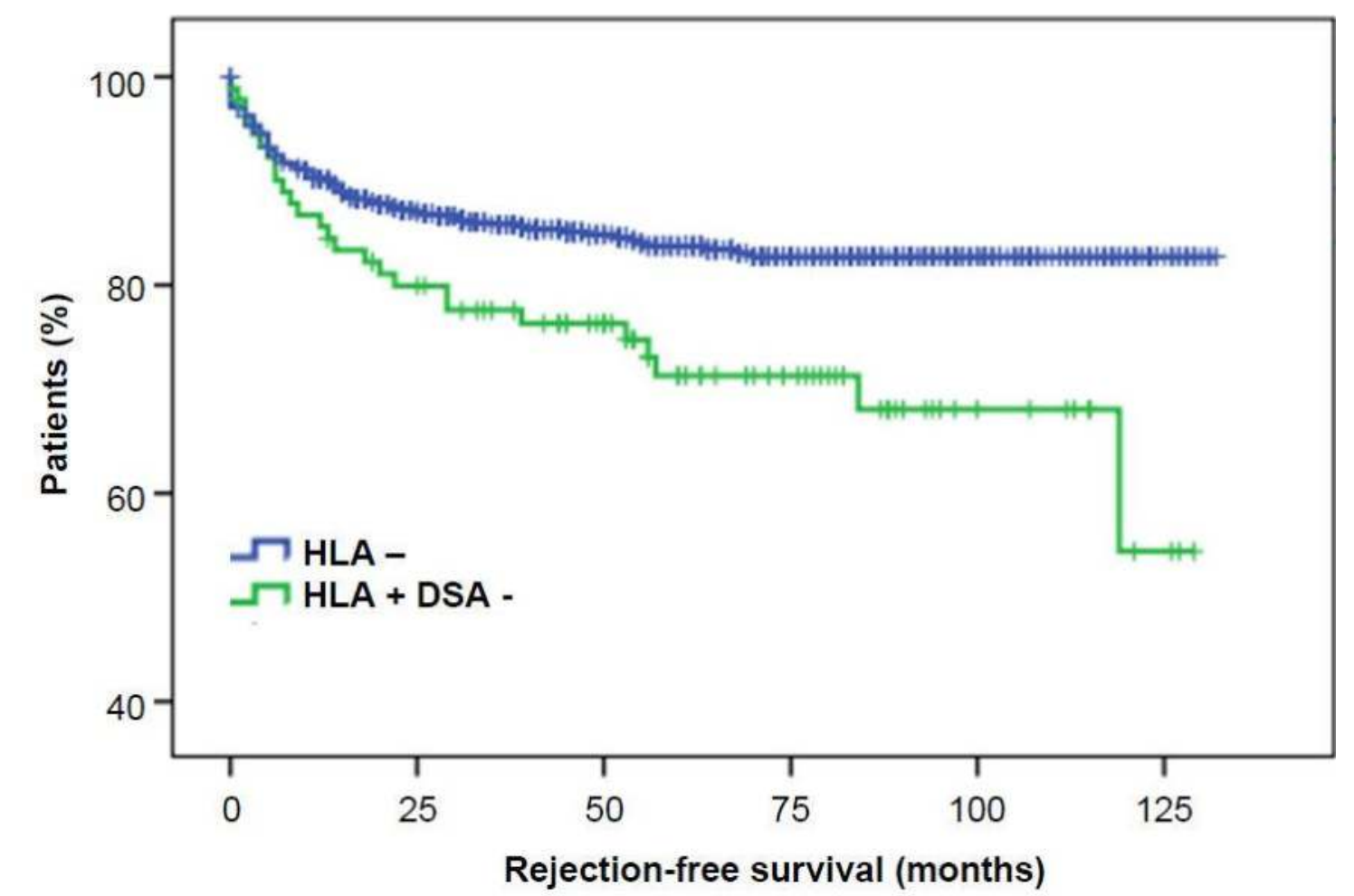

Fig 1. A comparison of Rejection-Free Survival in the presence of ndHLA

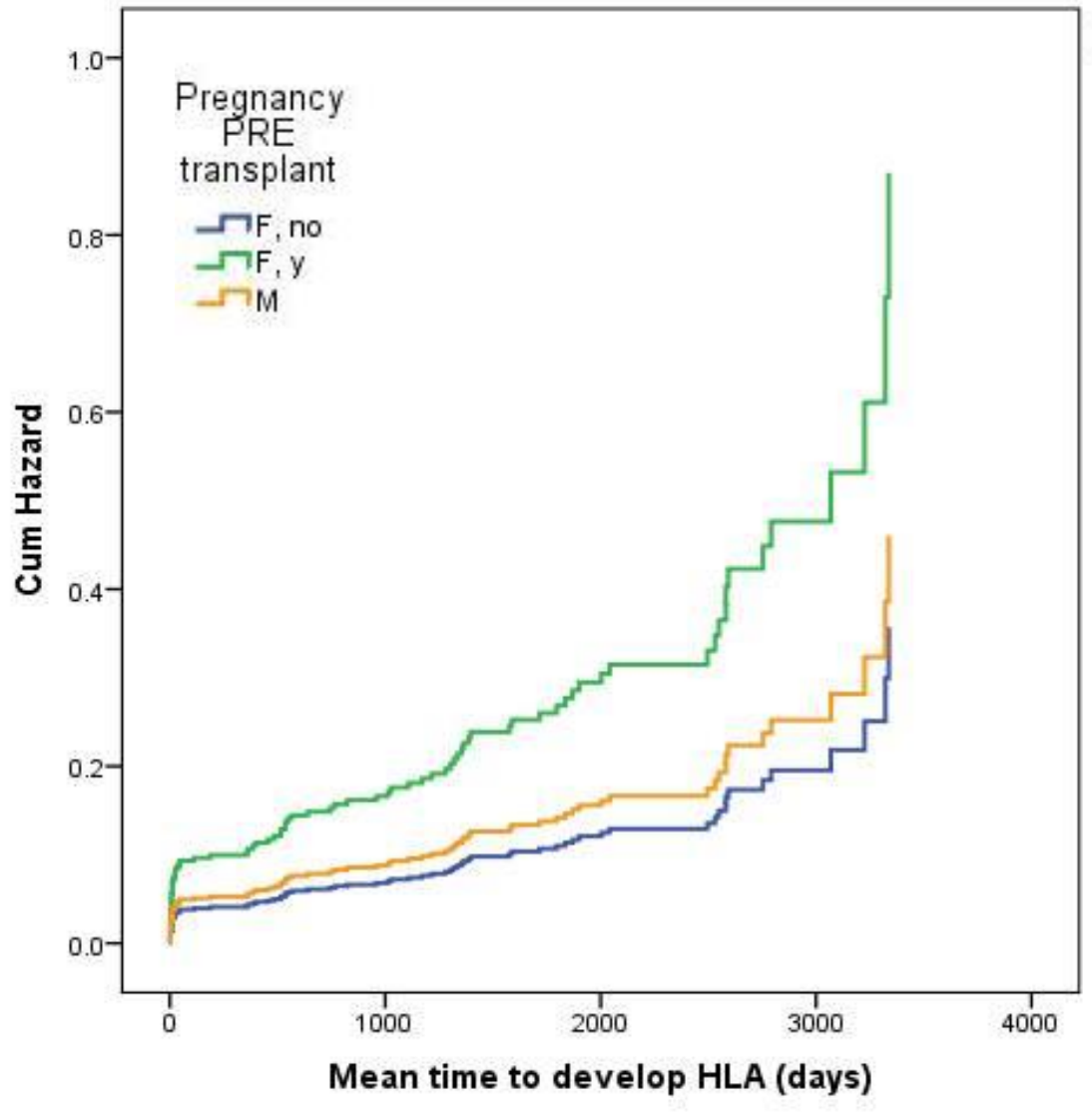

Fig 2. Mean time of ndHLA development

\section{Discussion:}

1. The presence of non donor directed HLA in unsensitised patients is associated with a significant risk of rejection and graft loss.

2. Previous pregnancies and transfusions within the first year of transplantation are associated with their development. 